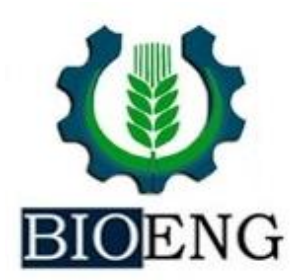

\title{
AQUISIÇÃO DE TERRAS RURAIS BRASILEIRAS COM A PARTICIPAÇÃO DE ESTRANGEIROS: UMA ANÁLISE DAS RESTRIÇÕES JURÍDICAS, DA JURISPRUDÊNCIA E DOS POSSÍVEIS IMPACTOS ECONÔMICOS DECORRENTES AO AGRONEGÓCIO
}

\author{
U. G. F. Tamarindo*, G. Pigatto, S. S. Braga Junior \\ UNESP - Univ. Estadual Paulista, Faculdade de Ciências e Engenharia, Tupã, SP, Brasil
}

Article history: Received 06 July 2017; Received in revised form 27 August 2017; Accepted 04 September 2017; Available online 29 September 2017.

\begin{abstract}
RESUMO
A compra de terras rurais nacionais, especialmente com a participação de estrangeiros no comando de empresas brasileiras, é questão controversa, notadamente por envolver o debate acerca de importantes estratégias econômicas e, sobretudo, de segurança e soberania nacional. O tema está atualmente normatizado especialmente pelas leis federais 4.504/64, 5.709/71 e 6.634/79, assim como pelos Decretos 74.965/74 e 85.064/80 e pela Instrução Normativa Incra no 76/2013. Contudo, após várias interpretações formuladas a respeito da matéria, a Advocacia-Geral da União, hodiernamente, orienta o governo brasileiro a manter restrições no que concerne à compra de terras rurais nacionais também às empresas brasileiras, da qual participem, a qualquer título, pessoas estrangeiras físicas ou jurídicas que tenham a maioria do seu capital social e residam ou tenham sede no exterior. Não obstante, a doutrina e a jurisprudência ainda divergem acerca do exato alcance das limitações impostas pela Lei no 5.709/71, e com isso permanece o cenário de insegurança jurídica que tem feito com que investimentos sejam postergados e, até mesmo, direcionados a outros países da América Latina e da África. Portanto, o presente trabalho tem por objetivo analisar os requisitos legais para aquisição de terras rurais brasileiras com a participação de estrangeiros, assim como, contextualizar o atual cenário legal e jurisprudencial e, por fim, pontuar os possíveis impactos econômicos diretos ao agronegócio.
\end{abstract}

Palavras-chave: Terras rurais. Aquisição. Estrangeiros. Limitações.

\section{ACQUISITION OF BRAZILIAN RURAL LAND WITH FOREIGN PARTICIPATION: AN ANALYSIS OF MAIN LEGAL RESTRICTIONS, JURISPRUDENCE AND POSSIBLE ECONOMIC IMPACT DUE TO AGRIBUSINESS}

\begin{abstract}
The purchase of rural land, especially with the participation of foreigners in charge of Brazilian companies, is a controversial issue, mainly because it involves the debates about important economic strategies and, above all, national security and sovereignty. The issue is normative on federal laws 4.504/64, 5,709/71 and 6.634/79, as well as Decrees 74.965/74 and 85.064/80 and Normative Instruction No. 76/2013. However, after a number of interpretations on the subject, the Union General Advocacy directs the Brazilian government to maintain

\footnotetext{
* ubirajaratamarindo@gmail.com

$O$ artigo foi originalmente apresentado no $55^{\circ}$ Congresso da Sociedade Brasileira de Economia, Administração e Sociologia Rural (SOBER), Santa Maria (RS), 2017

A participação no evento contou com financiamento da FAPESP (Processo 2017/08922-5)
} 
restrictions on the purchase of non-inclusive rural land to Brazilian companies, in which foreign legal entities that have a majority of their capital and reside or are headquartered abroad. Nevertheless, the doctrine and jurisprudence still diverge on the threshold of the limitations imposed by Law 5.709/71, and so, there is a scenario of legal uncertainty that has made the investments to be postponed and even directed to other countries of Latin America and Africa. Therefore, the objective of this paper is to characterize the legal requirements for the acquisition of Brazilian rural land with the participation of foreigners, as well as the current legal and jurisprudential scenario and, finally, to point out the possible direct economic impacts on agribusiness.

Keywords: Rural lands. Acquisition. Foreigners. Limitations

\section{INTRODUÇÃO}

Com exceção dos imóveis pertencentes à União, não existe qualquer restrição na legislação nacional em relação à compra de imóveis urbanos brasileiros por estrangeiros, de modo que este pode ou não ser residente no País.

Contudo, quando se trata de aquisição de terras rurais brasileiras por estrangeiros, o tema torna-se controverso e bastante discutido atualmente na sociedade, no Poder Judiciário e no Congresso Nacional, notadamente em razão dos investimentos que podem ser aportados ou que já deixaram de ser carreados ao agronegócio brasileiro, assim como das demais questões de estratégia econômica, segurança e de soberania nacional.

No campo legal, o atual texto da Constituição Federal traz uma previsão geral de limitações em seus artigos $190^{2} \mathrm{e}$ $172^{3}$. Também deverá ser observada nesta matéria a Lei 4.504/64, que é o Estatuto da Terra, e prevê a base do regime jurídico do imóvel rural. Além disso, a Lei 5.709/71 e o Decreto 74.965/74 estabelecem as principais regras para aquisição de imóvel rural por estrangeiro, enquanto a Lei 6.634/79 e o Decreto 85.064/80 dispõem acerca do regime jurídico de aquisição de

\footnotetext{
${ }^{2}$ Art. 190. A lei regulará e limitará a aquisição ou o arrendamento de propriedade rural por pessoa física ou jurídica estrangeira e estabelecerá os casos que dependerão de autorização do Congresso Nacional.

${ }^{3}$ Art. 172. A lei disciplinará, com base no interesse nacional, os investimentos de capital estrangeiro, incentivará os reinvestimentos e regulará a remessa de lucros.
}

imóvel rural localizado na faixa de fronteira.

Esse arcabouço jurídico impõe diversos controles à aquisição de terras rurais com a participação de estrangeiros, notadamente o art. $1^{\circ}, \S 1^{\circ}$, da Lei $\mathrm{n}^{\circ}$ 5.709/71, que estabelece limitações à pessoa jurídica brasileira da qual participem, a qualquer título, pessoas estrangeiras físicas ou jurídicas que tenham a maioria do seu capital social e residam ou tenham sede no exterior.

Nesse contexto, cumpre registrar, inicialmente, que os investimentos estrangeiros no agronegócio tiveram importante crescimento a partir do ano de 1994, tendo em vista, especialmente, a orientação exarada pela Advocacia-Geral da União no Parecer AGU GQ-22/1994, que, em breve síntese, entendeu que as pessoas jurídicas brasileiras, ainda que tivessem controle acionário de estrangeiros, não estariam adstritas às limitações específicas a estrangeiros estabelecidas pelo art. $1^{\circ}, \S 1^{\circ}$, da Lei n. ${ }^{\circ}$ 5.709/71. Com isso, estariam liberadas para comprar terras rurais sem as limitações estabelecidas aos estrangeiros.

Entretanto, após o reexame do contexto econômico e da alteração da Constituição Federal, a Advocacia-Geral da União, no ano de 2010, modificou seu posicionamento em relação às restrições estabelecidas à aquisição de terras rurais com a participação de estrangeiros. Diante disso, passou-se a defender a tese de aplicação integral dos limites estabelecidos pela Lei 5.709/91 aos estrangeiros 
residentes no País, às pessoas jurídicas estrangeiras autorizadas a funcionar no Brasil, assim como à pessoa jurídica brasileira da qual participem, a qualquer título, pessoas estrangeiras físicas ou jurídicas que tenham a maioria do seu capital social e residam ou tenham sede no exterior (Parecer CGU/AGU no 01/2008RVJ, Parecer CGU/AGU LA-01/2010).

Portanto, vê-se, a princípio, que a Advocacia-Geral da União defendeu, por mais de 20 anos, o entendimento de que o art. $1^{\circ}, \S 1^{\circ}$, da Lei no $5.709 / 71$, não fora recepcionado pelo atual texto constitucional. E, a partir do novo posicionamento firmado no ano de 2010 , lançado nos pareceres CGU/AGU no 01/2008-RVJ e CGU/AGU LA-01/2010, devidamente aprovados pela Presidência da República em 19 de agosto de 2010, consolidou-se, no Poder Executivo, o entendimento acerca da constitucionalidade dos controles estabelecidos pela Lei no 5.709/71.

Essa situação, contudo, tem gerado ampla discussão no Poder Judiciário com relação à distinção realizada entre empresas brasileiras, notadamente com controle estrangeiro, assim como, a extensão das limitações impostas pela Lei n- 5.709/71.

Outro aspecto de extrema relevância nesse contexto é alertado por Hage, Peixoto e Vieira Filho (2012), Gilio

\section{METODOLOGIA}

Considerando o objetivo de analisar os requisitos legais para aquisição de terras rurais brasileiras com a participação de estrangeiros, o presente estudo realizou uma abordagem qualitativa, podendo ainda ser classificado como bibliográfica e documental. As informações apresentadas foram obtidas por meio de revisão da literatura científica, assim como da legislação, doutrina e jurisprudência.

Ressalte-se, ademais, que a análise do direito positivo, assim compreendido como o universo das normas jurídicas vigentes no ordenamento jurídico brasileiro, dar-se-á pela adoção da et al. (2016), Barros e Pêssoa (2011) e Moka (2015), no sentido de que o efeito prático dessa disputa já resultou na redução de investimentos estrangeiros tanto na atividade rural quanto na agroindustrial, bem como, no redirecionamento de capital estrangeiro, a princípio programados para o Brasil, a outros países da América Latina e da África.

Não obstante os possíveis prejuízos ao agronegócio, Sauer e Leite (2012), citados por Gilio et al. (2016), o Instituto Nacional de Colonização e Reforma Agrária - INCRA (2008) e órgãos militares apoiam, expressamente, a imposição de limites à aquisição de terras rurais por estrangeiros, sobretudo ao argumento da necessidade de se assegurar, na sua plenitude, a segurança e soberania nacional, assim como que o Estado deve, de fato, promover maior controle sobre à aquisição e posse de terras, priorizando a reforma agrária e a soberania alimentar e fundiária.

Diante desse cenário, além de contextualizar esse debate, o objetivo deste artigo é analisar os requisitos legais para aquisição de terras rurais brasileiras com a participação de estrangeiros, bem como delinear $o$ atual cenário legal $\mathrm{e}$ jurisprudencial e, por fim, pontuar os possíveis impactos econômicos diretos ao agronegócio.

linguagem científica pertinente à ciência do direito, razão pela qual será adotado, também, o método analítico, que resulta do exame sistemático das normas jurídicas positivas, dos princípios, da teoria do direito, da doutrina e da jurisprudência (administrativa e judicial) em face dos fatos e hipóteses que se pretende analisar.

\section{Requisitos e limitações legais para a compra de terras rurais com a participação de estrangeiros}

A venda de terras rurais a estrangeiros não é fato novo no Brasil. Ao 
contrário, em alguns momentos da história inclusive foi incentivada, notadamente na década de 1990, com a inclusão do Brasil nos mercados globalizados e com a abertura para a importação e a investimentos estrangeiros.

Entretanto, no caso em análise, ainda que possuam roupagem formal de empresa brasileira, é certo que, em algumas situações, resta evidente a possível falta de controle na venda de terras rurais nacionais ao capital estrangeiro. É o caso, por exemplo: (a) da empresa de celulose Veracel, que possui capital da empresa sueco-finlandesa Stora Enso e adquiriu nada menos que $203 \mathrm{mil}$ hectares no Sul da Bahia; (b) da agropecuária $\mathrm{O}$ Telhar, ligada à multinacional argentina El Tejar, que cultiva soja, milho e algodão, e adquiriu 40 mil hectares e arrendou ainda outros 140 mil, no Estado de Mato Grosso do Sul; (c) da papeleira norte-americana Internacional Paper, que possui 16,9 mil hectares no Estado de Mato Grosso do Sul; (d) da empresa norte-americana Agroreservas, que comprou 29 mil hectares no Estado de Minas Gerais (CORREIO BRAZILIENSE, 2010).

De se destacar, também, o caso de empresas estrangeiras que atuam no setor sucroenergetico, podendo-se citar, por exemplo, a Louis Dreyfus, a Bunge, a Abengoa e a Cargill, que adquiriram e arrendaram áreas rurais nos estados do Sudeste e no Centro-Oeste, para cultivo especialmente de cana de açúcar (GILIO et al., 2016).

Há, ainda, empresas norteamericanas, europeias e asiáticas que compraram grandes porções de terras na região norte do País, como é o caso da GETHAL, de capital sueco e norteamericano, que possui mais de 160 mil hectares na Amazônia, para exploração de madeiras e de seus derivados.

Outras empresas têm como objeto social a criação de animais e exploração de plantas, para fins medicinais e de cosméticos. Essas situações, aliás, fomentam frequentes discussões a respeito da biopirataria praticada na Amazônia brasileira (INCRA, 2008).

Além disso, Nakatani et al. (2012), citados por Gilio et al. (2016), registraram que grupos chineses têm atuado fortemente no território nacional, por meio de fundos de investimentos e de empresas agropecuárias, para aquisição de grandes porções de terras rurais especialmente nos estados do Maranhão, Tocantins, Piauí e na região sul do País. Aliás, esse foi o motivo preponderante de o governo Dilma Rousseff ter aprovado o entendimento restritivo adotado pela Advocacia-Geral da União, ou seja, o temor do domínio chinês na agropecuária no País (FARIELLO, 2016).

Ainda assim, segundo informações do Instituto Nacional de Colonização e Reforma Agrária (INCRA), os estrangeiros possuem menos $1 \%$ dos imóveis rurais cadastrados no País, com maior concentração nas regiões Norte, CentroOeste e Sudeste, enquanto as terras indígenas, por exemplo, ocupam 12,6\% das terras brasileiras (TAVARES, 2013).

Não obstante, ao mesmo tempo em que se deseja os bilhões de dólares e de euros em investimentos estrangeiros para o agronegócio, é fato que o governo brasileiro está atento, em contrapartida, aos riscos que essa possível expansão desmensurada pode trazer à economia, assim como à própria segurança e soberania nacional.

Nesse passo, segundo Hodgson, Cullinan e Campbel (1999), citados por Hage, Peixoto e Vieira Filho (2012, p. 6):

[...] são inúmeras as razões que levam os Estados a adotarem políticas de restrição ao acesso de estrangeiros a terra. Dentre os principais motivos, além do nacionalismo e xenofobismo, pode-se destacar a segurança nacional, o domínio da infraestrutura, a prevenção contra a especulação estrangeira, a preservação do "tecido" social da nação, o controle dos investimentos diretos estrangeiros, a regulação da imigração, bem como a garantia do controle da produção de alimentos. 
Dito de outro modo, Pereira (2014, p. 33) pontua que um "Estado politicamente organizado sabe que a preservação de suas riquezas contra o interesse e o "ataque" externo tem grande importância para o incremento de seu desenvolvimento econômico e social, bem assim para o pleno exercício de sua soberania".

Ainda a esse respeito, cumpre destacar o item 7 do parecer da Consultoria-Geral da União CGU/AGU no01/2008-RVJ, aprovado pelo parecer da Advocacia-Geral da União AGU LA01/2010, revelando que a preocupação do governo brasileiro se reveste especialmente de caráter estratégico, já que a possível ausência de controle das aquisições de terras rurais por estrangeiros pode fomentar principalmente:
a) a expansão da fronteira agrícola com o avanço do cultivo em áreas de proteção ambiental e em unidades de conservação;
b) a valorização desarrazoada do preço da terra e incidência da especulação imobiliária gerando aumento do custo do processo de desapropriação voltada para a reforma agrária, bem como a redução do estoque de terras disponíveis para esse fim;
c) o crescimento da venda ilegal de terras públicas; utilização de recursos oriundos da lavagem de dinheiro, do tráfico de drogas e da prostituição na aquisição dessas terras;
d) o aumento da grilagem de terras;
e) a proliferação de "laranjas" na aquisição dessas terras;
f) o incremento dos números referentes à biopirataria na Região Amazônica;
g) a ampliação, sem a devida regulação, da produção de etanol e biodiesel;
h) a aquisição de terras em faixa de fronteira pondo em risco a segurança nacional.

Nesse contexto, o art. 190, da Constituição Federal de 1988, estabeleceu que a "lei regulará e limitará a aquisição ou o arrendamento de propriedade rural por pessoa física ou jurídica estrangeira e estabelecerá os casos que dependerão de autorização do Congresso Nacional [...]".

Em relação a essas diretrizes, segundo Pereira (2014, p. 35-36), o "preceituado pelo art. 190 da Constituição Federal levou em conta, portanto, a importância do imóvel rural para o país, de modo que o estrangeiro dele não se assenhore indiscriminadamente como proprietário ou arrendatário".

Por sua vez, a matéria foi normatizada e regulamentada especialmente pela Lei no $5.709 / 71$ e pelo Decreto $\mathrm{n}^{\circ} 74.965 / 74$, antes, porém, da promulgação do atual texto constitucional, que se deu em 5 de outubro de 1988. Portanto, como ver-se-á neste artigo, o que se discute, ainda, é se essa lei foi recepcionada integralmente pela nova ordem constitucional, e, consequentemente, suas diretrizes e limitações. Ademais, complementam o arcabouço jurídico a Lei 6.634/79 e o Decreto 85.064/80, que dispõem acerca do regime jurídico da aquisição de imóvel rural localizado na faixa de fronteira.

Dessa maneira, a legislação estabelece, dentre outras coisas, que o estrangeiro pessoa física, residente no País, bem como a pessoa jurídica estrangeira autorizada a funcionar no Brasil, só poderão adquirir imóvel rural:

a) na forma prevista na Lei $n^{\circ}$ 5.709/71 (art. $\left.1^{\circ}\right)$;

b) com a comprovação de a pessoa jurídica ter residência no País ou a pessoa jurídica estar autorizada a funcionar no Brasil, nos termos da legislação da Lei no 5.709/71 (art. 1º); c) com limitações quanto ao tamanho da propriedade a ser adquirida pelo estrangeiro $\left(\operatorname{art} .3^{\circ}\right.$ );

d) com percentual em loteamentos rurais efetuados por empresas particulares de colonização (art. $4^{\circ}$ );

e) com a necessidade de vinculação dos imóveis rurais adquiridos aos objetivos estatutários das pessoas jurídicas estrangeiras ou brasileiras a elas equiparadas $\quad\left(\right.$ art. $\left.5^{\circ}\right)$;

f) com a necessidade de assentimento prévio da SecretariaGeral do Conselho de Segurança Nacional na aquisição de imóveis em 
área considerada indispensável à segurança nacional $\left(\operatorname{art.~} 7^{\circ}\right)$

g) com a necessidade de a aquisição ser feita somente mediante escritura pública (art. $\left.8^{\circ}\right)$;

h) com a necessidade de previsão de elementos especiais que na escritura pública $\quad\left(\right.$ art. $\left.9^{\circ}\right)$;

i) com a necessidade de previsão de cadastro especial nos Cartórios de Registro de Imóveis (art. 10);

j) com a necessidade de controle das aquisições, com informações periódicas ao Ministério da Agricultura e à Secretaria-Geral do Conselho de Segurança Nacional (art. 11);

k) com a limitação quanto à extensão do total de terras pertencentes a estrangeiros limitada a um quarto da superfície do Município (art. 12);

1) com a vedação de doação de terras da União e dos Estados a pessoas físicas ou jurídicas estrangeiras (art. 14).

Além da necessidade específica de a pessoa física ter residência no País e a pessoa jurídica estar devidamente autorizada a funcionar no Brasil (art. $1^{\circ}$, da Lei 5.709/71), assim como de o imóvel estar devidamente registrado no Cartório de Registro de Imóveis e cadastrado no Sistema Nacional de Cadastro Rural (SNCT), há, especificamente, as seguintes limitações de área à pessoa estrangeira natural com residência no País:

a) até 50 MEI (Módulo de Exploração Indefinida - A dimensão do MEI varia entre 5 a 100 hectares, de acordo com a Zona Típica de Módulo (ZTM) do município de localização do imóvel rural $^{4}$ ) -, sendo que até 3 MEI não é necessária qualquer autorização do Incra (art. $7^{\circ}$,

\footnotetext{
${ }^{4}$ Exemplos: $1 \mathrm{MEI}=5$ ha em Camaçari $(\mathrm{BA}) \Rightarrow \mathrm{PF}=$ 250 ha (50 MEI); PJ=500 ha (100 MEI); $1 \mathrm{MEI}=55$ ha em Juara $(\mathrm{MT}) \Rightarrow \mathrm{PF}=$ 2.750 ha (50 MEI); $\mathrm{PJ}=5.500$ ha $(100 \mathrm{MEI})$; $1 \mathrm{MEI}=70$ ha em Japurá $(\mathrm{AM}) \Rightarrow \mathrm{PF}=$ 3.550 ha (50 MEI); PJ= 7.000 ha (100 MEI); $1 \mathrm{MEI}=55$ ha em São Félix do Xingu (PA) $\Rightarrow P F=2.750$ ha $(50 \mathrm{MEI}) ; \mathrm{PJ}=5.500$ ha $(100 \mathrm{MEI})$; $1 \mathrm{MEI}=15$ ha em Andradina $(\mathrm{SP}) \Rightarrow \mathrm{PF}=$ 750 ha (50 MEI); PJ= 1.500 ha (100 MEI); $1 \mathrm{MEI}=10$ ha em Passo Fundo $(\mathrm{RS}) \Rightarrow \mathrm{PF}$ $=500$ ha $(50 \mathrm{MEI}) ; \mathrm{PJ}=1.000$ ha $(100 \mathrm{MEI})$. (INCRA, 2008)
}

$\S 1^{\circ}$, Decreto 74.965/74), salvo no caso de aquisição de mais de um imóvel $\left(\S 3^{\circ}\right)$.

b) imóvel rural entre 4 e 20 MEI deverá haver autorização do Incra (art. $7^{\circ}, \S 2^{\circ}$, Decreto 74.965/74).

c) imóvel rural entre 21 e $50 \mathrm{MEI}$ deverá haver autorização do Incra e aprovação de projeto de exploração pelo Ministério do Desenvolvimento Agrário (art. $7^{\circ}, \S 4^{\circ}$, Decreto 74.965/74).

d) imóvel com mais de 50 MEI - a aquisição dependerá de autorização do presidente da República, ouvido o Conselho de Segurança Nacional vinculado ao Ministério da Defesa (art. $7^{\circ}, \S 5^{\circ}$, Decreto 74.965/74) ou autorização do Congresso Nacional (art. 23, § 2 ${ }^{\circ}$, da Lei 8.629/93).

e) não se aplica as restrições da legislação aos casos de sucessão legítima, com ressalva apenas para os imóveis localizados em faixa de fronteira ou em área de segurança nacional.

f) No tocante à pessoa jurídica estrangeira, com permissão para atuar no País, ou brasileira, com maioria de capital estrangeiro, pode adquirir:

g) imóvel rural até $100 \mathrm{MEI}$, que deve ser destinado à implantação de projetos agrícolas, pecuários, industriais ou de colonização, vinculados aos seus objetivos estatutários (art. 5, Lei 5.709/71) e deve haver aprovação de projeto de exploração pelo Ministério do Desenvolvimento Agrário, ouvido o Órgão Federal competente responsável pelas respectivas atividades (art. $5^{\circ}, \S 1^{\circ}$, Lei 5.709/71 c/c o art. $14, \S 1^{\circ}$, Incra IN 76/2013); h) se o empreendimento tiver por objeto área maior que cem módulos de exploração, a aquisição dependerá de autorização do presidente da República, ouvido o Conselho de Segurança Nacional - vinculado ao Ministério da Defesa (art. $7^{\circ}, \S 5^{\circ}$, Decreto 74.965/74) ou autorização do Congresso Nacional (art. 23, § $2^{\circ}$, da Lei 8.629/93).

Acrescente-se, ainda, que a soma das áreas rurais pertencentes a pessoas estrangeiras natural ou jurídica não pode ultrapassar 1/4 (25\%) da área do município onde o imóvel se situe. Da mesma forma, pessoas da mesma nacionalidade não 
poderão ser proprietárias de mais de $10 \%$ da área do município (Lei no 5.701/71).

Portanto, os principais requisitos estabelecidos para aquisição de imóvel rural por estrangeiro são: ter residência no País e a pessoa jurídica estrangeira estar devidamente autorizada a funcionar no Brasil, assim como a observância das limitações especialmente impostas pela Lei no 5.709/71, pelo Decreto $n^{\circ} 74.965 / 74$ e pela Instrução Normativa do Incra n76/2013.

Ainda a esse respeito, Pereira (2014, p. 48) pontua que para "residir no país o estrangeiro deve submeter-se às exigências do Estatuto do Estrangeiro, e para funcionar no Brasil, a pessoa jurídica estrangeira sujeitar-se-á dentre outros itens, ao que dispõe o Código Civil na parte que trata da sociedade estrangeira".

Com isso, as pessoas físicas residentes no exterior que possuam imóveis no Brasil devem ter inscrição no $\mathrm{CPF} / \mathrm{MF}$, enquanto as pessoas jurídicas, que não tenham estabelecimento no País, deverão ter inscrição no $\mathrm{CNPJ} / \mathrm{MF}$, a teor dos art. $3^{\circ}$, XII, "a", da IN-RFB $\mathrm{n}^{\circ}$ 864/2008, e art. 11, XIV, "a”, da IN-RFB no 748/2007 (DUARTE; ALVES, 2014).

Outro aspecto relevante diz respeito ao Tratado de Amizade, Cooperação e Consulta entre a República Federativa do Brasil e a República Portuguesa, de 22 de abril de 2000, e promulgado pelo Decreto 3.927, de 19 de setembro de 2001, que confere aos cidadãos portugueses a equiparação aos brasileiros no tocante à livre aquisição e arrendamento de imóvel rural, caso apresentem capacidade civil segundo a lei brasileira, bem como, se mantiverem residência permanente no Brasil e estiverem em gozo da nacionalidade brasileira.

Além desses requisitos e restrições, o art. $1^{\circ}, \S 1^{\circ}$, da Lei no $5.709 / 71^{5}$,

\footnotetext{
${ }^{5}$ Art. $1^{\text {o }}$ - O estrangeiro residente no País e a pessoa jurídica estrangeira autorizada a funcionar no Brasil só poderão adquirir imóvel rural na forma prevista nesta Lei.

$\S 1^{\circ}$ - Fica, todavia, sujeita ao regime estabelecido por esta Lei a pessoa jurídica brasileira da qual participem, a qualquer título, pessoas estrangeiras
}

estabeleceu ficar sujeita aos mesmos controles estabelecidos por esta lei a pessoa jurídica brasileira da qual participem, a qualquer título, pessoas estrangeiras físicas ou jurídicas que tenham a maioria do seu capital social e residam ou tenham sede no exterior.

Aí está: esse é o principal ponto que atualmente tem gerado embates nos tribunais, visto que a referida redação haveria ampliado o conceito de empresa brasileira, assim como estabelecido distinção em tese vedada pelo texto constitucional vigente. $\mathrm{Na}$ prática, portanto, as pessoas jurídicas brasileiras, ainda que tenham controle acionário de estrangeiros, estão adstritas aos mesmos limites, controles e limitações estabelecidos pela legislação nacional em relação à compra de terras rurais por estrangeiros. Senão, vejamos.

\section{Debate jurídico em face das diretrizes estabelecidas pelo art. $1^{\circ}, \S 1^{\circ}$, da lei № $5.709 / 71$}

No momento em que a Lei no 5.709 foi editada, no ano de 1971, não havia um conceito de empresa brasileira estabelecido constitucionalmente, ou seja, esse conceito estava inserido em normas infraconstitucionais, de modo que eventuais restrições também poderiam ser admitidas com base na mesma legislação infraconstitucional $\left(\operatorname{art.} 1^{\circ}, \S 1^{\circ}\right.$, da Lei n5.709/71). E foi exatamente o que aconteceu.

No entanto, com a promulgação da Constituição Federal de 1988, entendeu-se que o conceito de empresa brasileira foi positivado em seu art. 171, que, por sua vez, considerava empresa brasileira a constituída sob as leis brasileiras e que tivesse sua sede e administração no País, bem como empresa brasileira de capital nacional aquela cujo controle efetivo estivesse em caráter permanente sob a titularidade direta ou indireta de pessoas físicas domiciliadas e residentes no País ou

físicas ou jurídicas que tenham a maioria do seu capital social e residam ou tenham sede no Exterior. 
de entidades de direito público interno, entendendo-se por controle efetivo da empresa a titularidade da maioria de seu capital votante e o exercício, de fato e de direito, do poder decisório para gerir suas atividades.

Vê-se, em cognição sumária, que a equiparação promovida pelo art. $1^{\circ}, \S 1^{\circ}$, da Lei 5.709/71, em tese não estava de fato em harmonia com as disposições constitucionais estabelecidas no art. $171 \mathrm{da}$ Constituição Federal de 1988.

Diante disso, a Advocacia-Geral da União, por meio do Parecer $n^{\circ}$ AGU/LA04/94, que foi adotado pelo parecer AGU GQ-22/1994, orientou o governo brasileiro no sentido de que a equiparação e ampliação do conceito de empresa brasileira, estabelecida pela Lei 5.709/91, não havia sido recepcionada pela Constituição Federal de 1998. Nesse sentido, destaca-se, a seguir, as principais razões consideradas pela Advocacia-Geral da União:

[...] 12. Antes do advento da Constituição de 1988, o conceito de empresa brasileira ou de sociedade nacional estava inserido em normas infraconstitucionais. Assim, o Decreto-lei $\mathrm{n}^{\mathrm{o}}$ 2.627, de 26 de setembro de 1940, no art. 60, mantido pelo art. 300 da Lei $n^{\circ} 6.404$, de 15 de dezembro de 1976, estabelece:

"Art. 60. São nacionais as sociedades organizadas na conformidade da lei brasileira e que têm no País a sede de sua administração."

13. Sempre se entendeu que o conceito de sociedade estrangeira era fornecido por exclusão, ou seja, sociedade estrangeira era aquela que não preenchia os requisitos legais da empresa brasileira. Por outro lado, a lei poderia, em determinados casos, exigir que todos os acionistas ou certo número deles fossem brasileiros, por expressa referência do parágrafo único do mesmo art. 60 .

14. Além disso, tendo em vista a inexistência de qualquer norma de nível constitucional que dispusesse sobre o assunto, era admissível que norma jurídica de mesma hierarquia pudesse alterar o conceito legal antes referido, de maneira geral ou parcial, isto é, apenas para determinados efeitos. Assim, havendo a Lei $n^{\circ}$
5.709, de 1971, sido editada sob a égide da Constituição de 69, que nada dispunha sobre conceito de empresa brasileira ou sociedade nacional, parece-me que nada se poderia opor, àquela época, à validade do $\S 1^{\circ}$ do art. $1^{\circ}$ da Lei $n^{o} 5.709 / 71$, que, em última análise, para os efeitos dessa lei, equiparava a pessoa jurídica brasileira, com participação majoritária de estrangeiro, pessoas físicas ou jurídicas, à empresa estrangeira.

[...] 16. Com a promulgação da Constituição de 1988, porém, a situação alterou-se profundamente. A própria Constituição, no art. 171, estabeleceu o conceito de empresa brasileira (inciso I) e de empresa brasileira de capital nacional (inciso II). No primeiro caso - empresa brasileira - manteve, em linhas gerais, o conceito do art. 60 do Decreto-lei 2.627, de 1940, com pequenas alterações.

No segundo caso - empresa brasileira de capital nacional - adotou, também em linhas gerais, o conceito de empresa nacional constante do art. 12 da Lei $n^{\circ} 7.232$, de 29 de outubro de 1984 (antiga Lei de Informática).

17. O conceito de empresa estrangeira continuou a ser fornecido por exclusão, ou seja, empresa estrangeira será aquela que não preencher os requisitos de empresa brasileira.

18. Estabelecido, na própria Constituição, o conceito de empresa brasileira, qualquer restrição às empresas que preencham os requisitos nela referidos somente poderão existir nos casos expressamente previstos na mesma Constituição. Da análise do art. 171 da Constituição resulta a convicção de que ela não deixou margem ao legislador infraconstitucional para estabelecer restrições à empresa brasileira. O que se verifica, dos $\S \S 1^{\circ}$ e $2^{\circ}$ do mesmo artigo, é que se estabelecem vantagens para a empresa brasileira de capital nacional, sem qualquer referência, porém, a restrições à empresa brasileira.

19. Por outro lado, o art. 190 da Constituição de 1988 estabelece:

"Art. 190. A lei regulará e limitará a aquisição ou o arrendamento de propriedade rural por pessoa física ou jurídica estrangeira e estabelecerá os 
casos que dependerão de autorização do Congresso Nacional."

20. Verifica-se, de plano, que o que cabe à lei é regular e limitar a aquisição de propriedade rural por pessoa física ou jurídica estrangeira. Parece-me induvidoso, também, que os casos que dependerão de autorização do Congresso Nacional, a serem estabelecidas por lei, dizem respeito àquelas mesmas pessoas físicas ou jurídicas estrangeiras, e não a quaisquer outros casos. A análise comparativa entre o $§ 34$ do art. 153 da Constituição de 69, já transcrito, e o art. 190 da atual Constituição demonstra, à saciedade, que o último é significativamente restrito em relação ao primeiro.

21. Dentro desse enfoque, parece-me indiscutível que o $\S 1^{\circ}$ do art. $1^{\circ}$ da Lei $n^{\circ} 5.709$, de 1971, conflita com o conceito exarado no inciso I do art. 171 da Constituição Federal, não tendo sido recepcionado. Não vejo, igualmente, guarida para a sobrevivência daquele dispositivo legal no art. 190 da Constituição. Em consequência, o art. 23 da Lei $n^{\circ}$ 8.629, de 25 de fevereiro de 1993 , inclusive seu $\S 2^{\circ}$, não tem aplicação a sociedades que não sejam estrangeiras, como as empresas brasileiras controladas por pessoas jurídicas estrangeiras".

Nesse enfoque, após a promulgação da Constituição Federal de 1988, qualquer empresa que cumprisse os requisitos estabelecidos em seu art. 171 seria considerada brasileira, e, portanto, qualquer restrição imposta a essa empresa somente teria legitimidade nos casos estabelecidos expressamente no texto constitucional. Com isso, não haveria que se estender às empresas consideradas brasileiras, ainda que com controle acionário de estrangeiros, quaisquer restrições à aquisição e ao arrendamento de imóveis rurais no Brasil (art. $1^{\circ}, \S 1^{\circ}$, da Lei no 5.709/71).

Entretanto, em 15/08/1995 adveio a Emenda Complementar no 06, que, por meio de seu art. $3^{\circ}$, revogou o art. 171 da Constituição Federal de 1988, eliminando, do ponto de vista constitucional, a diferença entre empresa brasileira de capital estrangeiro e empresa brasileira de capital nacional. A respeito do tema, Bastos (1996, p. 79-80) assevera que:

A importância da presente emenda não reside apenas nas transformações jurídicas que ela opera no nosso direito objetivo. Ela tem uma significação simbólica que transcende os seus aspectos meramente jurídicos, colocando um ponto final a uma distinção introduzida pela Constituição de 1988 entre empresa brasileira e empresa brasileira de capital nacional.

A esta última conferiam-se vantagens não acessíveis às empresas meramente brasileiras que, na verdade, eram controladas pelo capital externo. Não há nada que agrida mais o capital internacional do que a submissão a um regime jurídico diferenciado do previsto para as empresas nacionais.

O Texto maior anterior consagrava uma odiosa discriminação consistente em diferenciar uma empresa brasileira de uma empresa de capital nacional. E, a seguir, os $\S \S 1^{\circ}$ e $2^{\circ}$ traçavam diversos privilégios em favor da empresa brasileira de capital nacional.

Isso inviabiliza a livre concorrência, regime a qual essas empresas estão habituadas a se submeter, como há pouco de viu. Seria praticamente impossível o País levar a cabo qualquer política de globalização da economia com a odiosa discriminação que a redação do art. 171 comportava.

Essa emenda elimina o art. 171, que, portanto, deixa de existir no nosso direito constitucional. As demais transformações que ela introduz decorrem desse princípio fundamental, qual seja, da nãodistinção entre capital nacional e estrangeiro. Essa passa a gozar de igual estatuto ao do nacional. São proibidos, portanto, ônus ou privilégios que se lhes queria impor, a não ser o estabelecimento de condições regulamentadas para a entrada de capital externo no País.

Diante dessa revogação, bem como pelo fato daquele comando normativo haver sido preponderante na concepção do entendimento firmado no Parecer LA04/94, a Advocacia-Geral da União solicitou a revisão da matéria. 
Nesse passo, segundo entendimento esposado pela própria Advocacia-Geral da União à página 7 do Parecer CGU/AGU no01/2008-RVJ, aprovado pelo Parecer LA01/2010:

$\mathrm{O}$ raciocínio que teria levado à nova análise da questão pode ser resumido da seguinte forma: se o art. 171 que constitucionalizava o conceito de empresa brasileira e fixava sua distinção do de empresa brasileira de capital nacional havia sido revogado, estaria eliminada a barreira que impedia a fixação, por lei infraconstitucional, de restrições à atuação das empresas brasileiras.

Após realizar o reexame da matéria, a Advocacia-Geral da União alterou seu posicionamento e, por meio do Parecer CGU/AGU no 01/2008-RVJ de 03 de setembro de 2008, aprovado pelo Parecer LA-01, de agosto de 2010, passou a advogar a tese de que o art. $1^{\circ}, \S 1^{\circ}$, da Lei no $5.709 / 71$, foi recepcionado pela nova ordem constitucional.

Com isso, pacificou-se o entendimento de aplicação integral dos limites e controles estabelecidos pela Lei 5.709/71 aos estrangeiros residentes no País, às pessoas jurídicas estrangeiras autorizadas a funcionar no Brasil, assim como à pessoa jurídica brasileira da qual participem, a qualquer título, pessoas estrangeiras físicas ou jurídicas que tenham a maioria do seu capital social e residam ou tenham sede no Exterior.

No que concerne ao quanto restou decidido pelo Parecer CGU/AGU n01/2008-RVJ, Pereira (2014, p. 42) acrescenta ainda que:

[...] enquanto vigente, os termos do art. 171 da Constituição Federal e aqueles agasalhados pelo $\S 1^{\circ}$ do art. $1^{\circ}$ da Lei $\mathrm{n}^{\circ} 5.709 / 71$, frente ao que dispõe a Lei de Introdução ao Código Civil, notadamente o artigo que disciplina o processo de revogação de leis, depreende-se com facilidade que o preceito constitucional não revogou o ventilado preceito infraconstitucional.

Num primeiro momento é de se observar que um era o foco e a proposta do art. 171 da Constituição e outro, bem diferente, o do dispositivo constante do $\S 1^{\circ}$ do art. $1^{\circ}$ da Lei $5.709 / 71$.

Deste modo, ao tempo em que o art. 171 da Constituição se preocupava exclusivamente em conceituar o que era empresa brasileira (inc. I) e empresa brasileira de capital nacional (inc. II), o $\S 1^{\circ}$ do art. $1^{\circ}$ da Lei $5.709 / 71$ se propunha tão somente em regulamentar a questão da aquisição de imóvel rural por pessoa jurídica brasileira da qual participem, a qualquer título, pessoas estrangeiras físicas ou jurídicas que tenham a maioria de seu capital social e residam ou tenham sede no exterior. Assim, é facilmente observável que o art. 171 da Constituição Federal não revogou expressamente, nem se mostrou incompatível, menos ainda regulamentou inteiramente a matéria constante do supracitado $\S 1^{\circ}$ do art. $1^{\circ}$ da Lei 5.709/71, exatamente por regulamentar a matéria diversa e totalmente estranha à disciplina da norma inferior.

Na mesma direção, esclarece ainda que:

[...] como o art. 171 da Constituição não revogou o $\S 1^{\circ}$ do art. $1^{\circ}$ da Lei $5.709 / 71$, não há que se falar nem mesmo em sua repristinação quando do advento da Emenda Constitucional 6/95, que revogou o dispositivo superior.

Deste modo, a aquisição do imóvel rural por estrangeiro segue integralmente o preceituado pela Lei $5.709 / 71$, quer para a pessoa física residente no país, quer para a pessoa jurídica autorizada a funcionar no Brasil, quer ainda para a pessoa jurídica brasileira da qual participe, a qualquer título, pessoa física ou jurídica estrangeira, residente e com sede no exterior, e que detenha a maioria de seu capital social (PEREIRA, 2014, p. 44)

De outro lado, com a publicação do Parecer CGU/AGU no 01/2008-RVJ, todos os órgãos da Administração Pública Federal deverão seguir o que lá restou estabelecido, isso por conta de sua força vinculativa.

Além disso, conforme disposto na Portaria Interministerial no 4 , de 
25/01/2014 ${ }^{6}$, da Advocacia-Geral da União, que tem como principal objetivo regulamentar a aplicação dos Pareceres GQ-22/1994 e GQ-181/1998, às situações jurídicas ocorridas antes da publicação do Parecer AGU LA 01/2010, os efeitos da interpretação firmada no referido parecer, só terá validade a partir de sua publicação. Portanto, não houve alteração em relação às aquisições já efetivadas.

Como se isso tudo não bastasse, a Corregedoria Nacional de Justiça, diante do pedido de providências no 0002981 80.2010.02.00.0000, formalizado pela Procuradoria Regional da República - $5^{\mathrm{a}}$ Câmara de Coordenação e Revisão Patrimônio Público e Social do Ministério Público Federal, já havia emitido, em 13/07/2010, a seguinte recomendação:

[...] Ante o exposto, considerando as razões enunciadas pela Procuradoria da República e levando em conta a manifestação do Consultor-Geral devidamente aprovado pelo Advogado-Geral no âmbito da AGU tanto como atento às recomendações do Tribunal de Constas da União, esta Corregedoria Nacional de Justiça em face dos serviços

\footnotetext{
${ }^{6}$ PORTARIA INTERMINISTERIAL No - 4, DE 25 DE FEVEREIRO DE 2014.

[...] Art. $1^{\circ}$ A presente Portaria regula a aplicação do Parecer AGU/LA-01/2010 em processos ou procedimentos administrativos quando verificadas situações jurídicas aperfeiçoadas entre as datas de 7 de junho de 1994 e 22 de agosto de 2010.

Art. $2^{\circ}$ Para os fins desta Portaria será considerada situação jurídica aperfeiçoada a alienação de imóvel rural a pessoa jurídica equiparada a estrangeira quando:

I - objeto de escritura pública lavrada no período previsto no art. $1^{\circ}$, ainda que não registrada;

II - decorrer de aquisição de empresa, cujo instrumento de sucessão empresarial tenha sido depositado na Junta Comercial até a data de 22 de agosto de 2010, sem prejuízo da autorização ou escrituração que seja legalmente exigida, inclusive eventual aprovação da operação pelo Sistema Brasileiro de Defesa da Concorrência; e

III - feita no período previsto no art. $1^{\circ}$, porém cuja escrituração ou depósito tenha estado ou esteja na dependência de ato ou decisão a cargo de órgão da Administração Pública, a cuja demora não tenha dado causa a interessada.
}

judiciários auxiliares --
nomeadamente os serviços
notariais e registrais -- deve
recomendar fortemente a imediata
adoção pelas Corregedorias locais
ou regionais junto aos Tribunais
respectivos que determinem aos
Cartórios de Registro de Imóveis
e Tabelionatos de Notas que
façam observar rigorosamente as
disposições da Lei no 5.709 de
1971 quando se apresentarem ou
tiverem de lavrar atos de
aquisição de terras rurais por
empresas brasileiras com
participação majoritária de
estrangeiros, pessoas físicas ou
jurídicas.

$\mathrm{Na}$ sequência, esse mesmo posicionamento foi seguido pela Corregedoria Geral da Justiça do Estado de São Paulo que, em 09/09/2010, emitiu o Parecer n- 250/2010-E, fixando, dentre outras coisas, o seguinte comando normativo:

[...] Os delegados dos serviços notariais e registrais passem, doravante, a aplicar o disposto nos arts. $10,11,12, \mathrm{c} / \mathrm{c}$ o art. $1^{\circ}, \S 1^{\circ}$, todos da Lei $\mathrm{n}^{\circ} 5.709 / 71$, também no caso das empresas brasileiras com participação majoritária estrangeira, que venham a adquirir tais áreas rurais. Observe-se que os estrangeiros poderão figurar como pessoas jurídicas ou físicas (ficando a estas equiparadas as pessoas com elas casadas ou vivendo em união estável, se mediante comunhão de bens). Em tais casos, deve o registrador imobiliário efetuar o cadastramento no Portal do Extrajudicial, encaminhando cópia da planilha cadastrada e da respectiva matrícula para conferência, a esta Corregedoria Geral da Justiça, observando-se que tal lançamento deverá sempre ser efetuado em nome do estrangeiro, seja ele pessoa física ou jurídica: esteja ele figurando na qualidade de proprietário, de cônjuge ou companheiro em comunhão de bens ou, tão somente, de sócio ou acionista majoritário da empresa proprietária do imóvel rural. 
Não obstante esse cenário, começaram a surgir entendimentos diversos a esse no próprio Tribunal de Justiça do Estado de São Paulo - TJSP que, por meio de seu Órgão Especial, nos autos do Mandado de Segurança no 0058947-33.2012.8.26.0000 ${ }^{7}$, considerou que o art. $1^{\circ}, \S 1^{\circ}$, da Lei no $-5.709 / 71$, de fato não foi recepcionado pela Constituição Federal de 1988.

Em razão dessa decisão, a Corregedoria Geral da Justiça do Estado de São Paulo emitiu, em 05/12/2012, um novo parecer registrado sob no 461/2012-E, dispensando 8 os notários e registradores de

7 I - Mandado de Segurança contra ato do Corregedor Geral de Justiça de São Paulo que negou provimento ao recurso administrativo interposto pela impetrante.

II - Cabe direito líquido e certo da impetrante em face da decisão administrativa que, mudando interpretação jurídica, vedou averbação de ato de incorporação societária em Cartório de Registro de Imóveis da Comarca de Casa Branca.

III - O art. $1^{\circ}, \S 1^{\circ}$, da Lei $n^{\circ} 5.709 / 71$ não foi recepcionado pela Constituição de 1988, o que o torna não incidente a empresas brasileiras que tenham participação de capital estrangeiro.

IV - Não é passível a repristinação do referido artigo, com a revogação integral do art. 171 da Constituição Federal pela Emenda Constitucional $\mathrm{n}^{\circ} 06 / 95$.

V - A decisão coatora emanada após a realização concreta do negócio jurídico sucessivo da incorporação viola ato jurídico perfeito e direito adquirido, afrontando, também os princípios da isonomia e da segurança jurídica, sem dizer que fere de morte a interpretação sistemática e teleológica, bem como a moderna hermenêutica da ponderação dos interesses e da razoabilidade jurídica

VI - Sucessão a título universal a título de subscrição de capital não identifica o negócio de compra e venda imobiliária.

VII - Defere-se o writ, a fim de se ordenar averbação do ato de incorporação válido e eficaz, no álbum imobiliário de Casa Branca. (TJSP Mandado de Segurança n. ${ }^{\circ} 0058947$ 33.2012.8.26.0000, relator Desembargador: Guerrieri Rezende - Órgão Especial do Tribunal de Justiça de São Paulo - Data do Julgamento: 12/09/2012) g.n.

${ }^{8}$ [...] revejo a orientação normativa estabelecida com a aprovação do parecer n. ${ }^{\circ}$ 250/10-E, lavrado nestes autos (fls. 77/87 e 88), e reconheço, inclusive na linha do decidido pelo Colendo Órgão Especial do Egrégio Tribunal de Justiça de São Paulo (Mandado de Segurança n. ${ }^{\circ} 0058947-$ imóveis no Estado de São Paulo de observarem as restrições e determinações da Lei no 5.709/71.

Em sentido contrário, a Corregedoria Nacional de Justiça, por meio do Provimento no $43 / 2015$, de 17 de abril de $2015^{9}$, mais uma vez determinou aplicar-se integralmente a Lei 5.709/71 ao arrendamento de imóvel rural por estrangeiro residente ou autorizado a

33.2012.8.26.0000, relator Desembargador Guerrieri Rezende, julgado em 12.09.2012), que o $\S$ $1 .^{\circ}$ do artigo $1 .^{\circ}$ da Lei n. ${ }^{\circ} 5.709 / 1971$ não foi recepcionado pela Constituição Federal de 1988, de sorte, portanto, a dispensar os tabeliães e os oficiais de registro de observarem as restrições e as determinações impostas pela Lei n. ${ }^{\text {o }}$ 5.709/1971 e

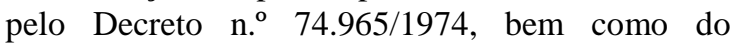
cadastramento no Portal do Extrajudicial, em relação às pessoas jurídicas brasileiras cuja maioria do capital social se concentre em poder de estrangeiros residentes fora do Brasil ou de pessoas jurídicas com sede no exterior.

\footnotetext{
${ }^{9}$ Provimento No 43 de 17/04/2015
}

Ementa: Dispõe sobre o arrendamento de imóvel rural por estrangeiro residente ou autorizado a funcionar no Brasil, bem como por pessoa jurídica brasileira da qual participe, a qualquer título, pessoas estrangeiras física ou jurídica que resida ou tenha sede no exterior e possua a maioria do capital social. (...)

CONSIDERANDO o Parecer CGU/AGU n. 01/2008 - RVJ, de 3 de setembro de 2008, aprovado e publicado no Diário Oficial da União do dia 23 de agosto de 2010, que revogou expressamente o Parecer n ${ }^{\circ}$ GQ-181, de 1998 e o Parecer GQ-22, de 1994,

RESOLVE

Art. $1^{\circ}$ Os contratos de arrendamento de imóvel rural serão necessariamente formalizados por escritura pública, quando celebrados por:

I - pessoa física estrangeira residente no Brasil;

II - pessoa jurídica estrangeira autorizada a funcionar no Brasil;

III - pessoa jurídica brasileira da qual participe, a qualquer título, pessoa estrangeira física ou jurídica que resida ou tenha sede no exterior e possua a maioria do capital social.

$\S 1^{\circ}$ Os tabeliães responsáveis pela lavratura de escritura pública relativa a arrendamento de imóvel rural, por pessoa constante do caput deste artigo, observarão o disposto no art. 23 da Lei $n^{\circ}$ $8.629 / 1993$, bem como os requisitos formais previstos nos artigos 92 e seguintes da Lei $n^{\circ}$ $4.504 / 1964$, regulamentada pelo Decreto $n^{\circ}$ 59.566/1966, e o art. 215 do Código Civil de 2002. (...) (Ministra NANCY ANDRIGHI - Corregedora Nacional de Justiça - 17/04/2015). 
funcionar no Brasil, bem como por pessoa jurídica brasileira da qual participe, a qualquer título, pessoa estrangeira física ou jurídica que resida ou tenha sede no exterior e possua a maioria do capital social.

Esse mesmo entendimento, aliás, restou acolhido também pelo Superior Tribunal de Justiça nos autos do Recurso Especial $n^{\circ} 1.273 .955$.

Abrindo um parêntese aqui, podemos verificar que, independentemente de todas essas divergências acerca do tema, uma questão é inegável: o impacto causado pelos pareceres CGU/AGU no 01/2008RVJ e CGU/AGU LA-01/2010 é deveras significativo para a economia do agronegócio. Tanto que, Hage, Peixoto e Vieira Filho (2012) e Barros e Pessôa (2011) afirmaram que houve redução nos investimentos estrangeiros na agricultura brasileira e prejuízos ao agronegócio na ordem de R\$ 15 bilhões somente no período de 2011 a 2012. Além disso, estavam previstos investimentos de aproximadamente $\mathrm{R} \$$ 93,5 bilhões na compra de terras e na implementação de infraestrutura operacional.

$\mathrm{Na}$ mesma direção, Gilio et al. (2016) apontam que esse contexto está repercutindo negativamente na tomada de decisão de investimento estrangeiro no setor sucroenergetico, que, por sua vez, já experimenta diminuição de novos projetos e até mesmo de ampliação daqueles já existentes.

Portanto, permanecendo esse cenário teme-se a transferência de produção e de investimentos agropecuários para outros países, assim como a desvalorização do preço da terra e a incidência da especulação imobiliária.

Não por outra razão, foi apresentado um projeto de lei no Senado Federal autuado sob no 590/2015, de autoria do senador Waldemir Moka, do Estado do Mato Grosso do Sul, que objetiva flexibilizar as restrições estabelecidas pela Lei 5.709/71. Segundo o senador, desde 2010 o setor agropecuário tem seu crescimento comprometido pelo parecer da AGU. Apenas o setor florestal (incluindo os segmentos de papel e celulose, siderurgia e painéis de madeira) teve perdas de aproximadamente $\mathrm{R} \$ 37,32$ bilhões em empreendimentos suspensos ou não realizados, seja pela paralisação de empreendimentos já existentes e em fase de desenvolvimento, ou já aprovados pelos empreendedores e em fase de aquisição ou registro em cartório, o que deixou de gerar cerca de 40 mil novos empregos (BRASIL, 2015).

Ademais disso, o referido projeto aponta, ainda, que a "insegurança jurídica, enquanto perdurar o Parecer AGU LA01/2010, está gerando um atraso em investimentos que certamente estão migrando para outros países" (PLS. 590/2015, p. 10).

Existe, ainda, o projeto de Lei no4059/2012 (apensado ao PL 2289/2007), de autoria da Comissão de Agricultura, Pecuária, Abastecimento e Desenvolvimento Rural, e relatoria do deputado Newton Cardoso Júnior, do Estado de Minas Gerais, que tramita perante a Câmara dos Deputados e visa regulamentar o art. 190, da $\mathrm{CF} / 88$ e, consequentemente, flexibilizar as limitações estabelecidas pela Lei 5.709/71.

Finalmente, há lugar, ainda, para mais uma observação no que concerne esse imbróglio jurídico: em 13 de setembro de 2016 o ministro Marco Aurélio, do Supremo Tribunal Federal (STF), concedeu uma medida liminar na Ação Cível Originária (ACO) 2463, proposta pelo Incra, para suspender os efeitos do parecer no 461/2012-E da Corregedoria Geral de Justiça do Estado de São Paulo, até final julgamento da ação.

A propósito, transcreve-se, a seguir, alguns dos fundamentos que levaram o ministro a conceder a medida liminar:

[...] Percebam as balizas objetivas do caso. $\mathrm{O}$ autor pretende a declaração de nulidade de ato da CorregedoriaGeral de Justiça do Estado de São Paulo mediante o qual se reconheceu a não recepção do artigo $1^{\circ}, \S 1^{\circ}$, da Lei $\mathrm{n}^{\mathrm{o}}$ 5.709/1971. O preceito restringe a aquisição de imóveis rurais por pessoas jurídicas brasileiras 
cuja maioria do capital social pertença a estrangeiros.

Observem a organicidade do Direito. A norma em jogo, embora controvertida no âmbito administrativo, não foi declarada inconstitucional pelo Supremo em processo objetivo. Ou seja, milita em favor do dispositivo a presunção de constitucionalidade das leis regularmente aprovadas pelo Poder Legislativo, tal como preconiza o Estado de Direito. É impróprio sustentar a não observância de diploma presumidamente conforme ao Diploma Maior com alicerce em pronunciamento de Tribunal local em processo subjetivo - mandado de segurança. Notem, a ressaltar essa óptica, que o ato atacado afastou a incidência, em apenas um Estado da Federação, de preceito de lei federal por meio da qual regulamentado tema inserido na competência da União artigo 190 da Constituição Federal -, atentando contra o pacto federativo.

A par desse aspecto, vê-se, em exame inicial, a existência de fundamentos na Carta Federal para o alcance das restrições previstas na Lei $\mathrm{n}^{\mathbf{0}}$ 5.709/1971. O Texto Maior, conquanto agasalhe os princípios da isonomia e da livre iniciativa, reservou ao legislador ferramentas aptas a assegurar a soberania, pressuposto da própria preservação da ordem constitucional.

A soberania, além de fundamento da República Federativa do Brasil, também constitui princípio da ordem econômica, evidenciando o papel no arranjo institucional instaurado em 1988. Expressou-se preocupação com a influência do capital estrangeiro em assuntos sensíveis e intrinsecamente vinculados ao interesse nacional. Daí o tratamento diferenciado previsto no artigo 190 da Lei Básica da República:

Art. 190. A lei regulará e limitará a aquisição ou o arrendamento de propriedade rural por pessoa física ou jurídica estrangeira e estabelecerá os casos que dependerão de autorização do Congresso Nacional.

A efetividade dessa norma pressupõe que, na locução "estrangeiro", sejam incluídas entidades nacionais controladas por capital alienígena. A assim não se concluir, a burla ao texto constitucional se concretizará, presente a possibilidade de a criação formal de pessoa jurídica nacional ser suficiente à observância dos requisitos legais, mesmo em face da submissão da entidade a diretrizes estrangeiras - configurando a situação que o constituinte buscou coibir.

3. Defiro a liminar pleiteada para suspender os efeitos do parecer $n^{\circ}$ 461/12-E da Corregedoria-Geral da Justiça de São Paulo, até o julgamento definitivo desta ação.

Não obstante, e inconformada com o posicionamento do ministro, a Sociedade Rural Brasil, atuando no processo na qualidade de amicus curiae ${ }^{10}$, apresentou recurso contra a decisão liminar. Contudo, o caso ainda está longe de uma definição, de modo que, na seara jurídica, caberá ao Supremo Tribunal Federal a palavra final a respeito da constitucionalidade da equiparação e das limitações às empresas brasileiras controladas por estrangeiros, e, no âmbito executivo e legislativo, ao Governo Federal e ao Congresso Nacional, que já possuem projetos de medida provisória e de leis visando permitir maiores investimentos no agronegócio com o abrandamento do rigor da Lei no $5.709 / 71$.

Por fim, há informações de que o presidente Michel Temer, em mais uma tentativa de reverter a crise econômica do País, prepara uma medida provisória para regulamentar e, sobretudo, facilitar a compra de terras rurais por estrangeiros. Entretanto, tal medida só não foi adotada ainda por conta da pressão que os órgãos militares estariam fazendo sobre $\mathbf{O}$ governo, tendo em vista que entendem que o projeto coloca em risco a soberania do País (FARIAS, 2016; TRUFFI, 2017).

10 Descrição do Verbete: "Amigo da Corte". Intervenção assistencial em processos de controle de constitucionalidade por parte de entidades que tenham representatividade adequada para se manifestar nos autos sobre questão de direito pertinente à controvérsia constitucional. Não são partes dos processos; atuam apenas como interessados na causa. Plural: Amici curiae (amigos da Corte) (STF, 2017). 


\section{CONSIDERAÇÕES FINAIS}

Diante das informações apontadas neste trabalho, foi possível constatar que a atual legislação estabeleceu vários requisitos e limitações à compra de terras rurais com a participação de estrangeiro, notadamente quando este tem o controle de empresa brasileira.

Além disso, verificou-se, ainda, que os investimentos estrangeiros na agricultura e na aquisição de terras rurais brasileiras cresceram de forma acentuada a partir da década de 1990, especialmente por conta da interpretação conferida pela Advocacia-Geral da União no Parecer AGU GQ-22/1994, que, dentre outras coisas, entendeu que as pessoas jurídicas brasileiras, ainda que tivessem controle acionário de estrangeiros, não estariam adstritas às disposições estabelecidas pelo art. $1^{\circ}, \S 1^{\circ}$, da Lei no $5.709 / 71$, que, por sua vez, impôs várias limitações à compra de terras rurais nacionais pelo capital estrangeiro.

Foi observado também que, por conta da alteração na Constituição Federal de 1988, promovida pela Emenda Complementar no 06, a Advocacia-Geral da União, reexaminando matéria, acabou conferindo nova interpretação ao caso e, por meio dos pareceres CGU/AGU no 01/2008-RVJ e CGU/AGU LA-01/2010, aprovados pela Presidência da República, passou a admitir, na compra de terras rurais por empresas brasileiras com $\mathrm{o}$ controle de capital estrangeiros, todas as limitações preconizadas no art. $1^{\circ}, \S 1^{\circ}$, da Lei n- 5.709/71.

Nesse ponto, restou demonstrado que, com a aplicação do art. $1^{\circ}, \S 1^{\circ}$, da Lei n- 5.709/71, ficaram sujeitas ao mesmo regime estabelecido por esta lei todas as pessoas jurídicas brasileiras da qual participem, a qualquer título, pessoas estrangeiras físicas ou jurídicas que tenham a maioria do seu capital social e residam ou tenham sede no Exterior.

Esse mesmo entendimento foi albergado tanto pela Corregedoria Nacional de Justiça, por meio do
Provimento no 43/2015, de 17 de abril de 2015, quanto pelo Superior Tribunal de Justiça, no bojo dos autos do Recurso Especial no 1.273.955.

Entretanto, em sentido contrário, o Tribunal de Justiça do Estado de São Paulo entende que o art. $1^{\circ}, \S 1^{\circ}$, da Lei no 5.709/71, não foi recepcionado pela Constituição Federal de 1988. Com isso, a Corregedoria Geral de Justiça do Estado de São Paulo, por meio do Parecer no461/2012-E, vem dispensando os notários e registradores de imóveis no Estado de São Paulo de observarem as restrições estabelecidas.

Não obstante, o ministro Marco Aurélio, do Supremo Tribunal Federal (STF), concedeu uma medida liminar na Ação Cível Originária (ACO) 2463, proposta pelo Incra, para suspender os efeitos do referido parecer paulista, até final julgamento da ação. Contudo, ainda não houve julgamento final de mérito pelo plenário da Suprema Corte.

Com isso, prevalecem, atualmente, todas as diretrizes e limitações estabelecidas principalmente na Lei no 5.709/71.

Todas essas divergências puderam ser contextualizadas de forma detalhada no decorrer do presente trabalho, sobretudo, os possíveis impactos econômicos causados pelos pareceres CGU/AGU n01/2008-RVJ e CGU/AGU LA-01/2010, aprovados pela Advocacia-Geral da União, a quem compete realizar consultoria e assessoramento jurídico ao Poder Executivo Federal, assim como a fixação da interpretação das leis e da Constituição quando há dúvidas e controvérsias jurídicas.

Nessa mesma direção, segundo estudos indicados por Hage, Peixoto e Vieira Filho (2012), Gilio et al (2016), Barros e Pêssoa (2011) e Moka (2015), houve repercussão negativa na tomada de decisão de novos investimentos estrangeiros no agronegócio brasileiro, enquanto que, por outro lado, o Instituto 
Nacional de Colonização e Reforma Agrária (2008), órgãos militares e Sauer e Leite (2012) apoiaram a imposição de limites aos estrangeiros.

Verificou-se, ainda, nesse contexto, que foi apresentado projeto de lei (PLS 590/2015) pelo senador Waldemir Moka, do Estado do Mato Grosso do Sul, que pretende flexibilizar as limitações estabelecidas pela Lei 5.709/71, sobretudo ao argumento de um impacto negativo de $\mathrm{R} \$ 37,32$ bilhões somente no setor florestal, assim como de possíveis prejuízos na ordem de $\mathrm{R} \$ 3,5$ bilhões em tributos não arrecadados.

Há, também, o projeto de lei no 4059/2012 (apensado ao PL 2289/2007), de autoria da Comissão de Agricultura, Pecuária, Abastecimento e Desenvolvimento Rural, de relatoria do deputado Newton Cardoso Júnior, do Estado de Minas Gerais, que tramita perante a Câmara dos Deputados e visa regulamentar o art. 190, da CF/88 e, consequentemente, flexibilizar as limitações estabelecidas pela Lei 5.709/71.

Por fim, não obstante as pressões políticas e sociais exercidas especialmente pelo INCRA e por órgãos militares, há informações extraoficiais de que $o$ presidente Michel Temer, com o objetivo de aumentar os investimentos estrangeiros no agronegócio brasileiro e, sobretudo, colaborar no reaquecimento da economia,

\section{REFERÊNCIAS BIBLIOGRÁFICAS}

BARROS, A. M.: PESSÔA, A. (Org.). Impactos econômicos do parecer da AGU, que impõe restrições à aquisição e arrendamento de terras agrícolas por empresas brasileiras com controle do capital detido por estrangeiros. São Paulo: Agroconsult e MB Agro, 2011. Disponível em:

http://www.souagro.com.br/agricultoresdefendem-liberdade-parainvestimentosestrangeiros. Acesso em: 12 nov. 2016;

BASTOS, C. R. Emendas à Constituição de 1988, Ed. Saraiva: 1996; prepara uma medida provisória visando facilitar a compra de terras rurais por estrangeiros (OLIVEIRA; FARIELLO, 2017).

A referida medida provisória a ser editada: a) possibilidade de o presidente da República, por decreto, estabelecer os "limites quantitativos globais" das propriedades que poderiam ser adquiridas por estrangeiros; b) não impor limites à soma de áreas rurais que uma empresa brasileira controlada por estrangeiros, direta ou indiretamente, podendo adquirir em uma mesma cidade; c) também não serão impostas cotas mínimas para culturas anuais, caso da soja, milho, algodão, etc.

Contudo, a medida provisória pretende vedar a aquisição de imóveis rurais por: a) organização nãogovernamental ou fundação particular com sede no exterior ou com orçamento anual proveniente, na sua maior parte, de uma mesma pessoa física estrangeira; $b$ ) empresas estrangeiras com sede no exterior e fundos soberanos constituídos por países estrangeiros (OLIVEIRA; FARIELLO, 2017).

Em conclusão, o cenário ainda é de incertezas para o investidor estrangeiro, especialmente para aqueles que pretendem investir no agronegócio brasileiro por meio de aquisição e exploração de terras rurais nacionais.

BRASIL. Advocacia-Geral da União. Parecer AGU GQ-181/1998. Brasília, 17 de dezembro de 1998;

BRASIL. Advocacia-Geral da União. Parecer AGU GQ-22/94. Brasília, 7 de junho de 1994;

BRASIL. Advocacia-Geral da União. Parecer LA-01/2010. Brasília, 19 de agosto de 2010;

BRASIL. Advocacia-Geral da União. Parecer LA-04/94. Brasília, 7 de junho de 1994; 
BRASIL. Advocacia-Geral da União. Portaria Interministerial $\mathrm{n}^{\circ} 4$. Brasília, 25 de fevereiro de 2014;

BRASIL. Câmara dos Deputados. Projeto de Lei no 4059/2012. Autoria: Comissão de Agricultura, Pecuária, Abastecimento e Desenvolvimento Rural. Disponível em: http://www.camara.gov.br/proposicoesWe b/fichadetramitacao?idProposicao $=548018$. Acesso em: 16 fev. 2017;

BRASIL. Consultoria-Geral da União. Parecer CGU/AGU no 01/2008. Brasília, 3 de setembro de 2008;

BRASIL. Corregedoria Nacional de Justiça. Pedido de Providencias no0002981-80.2010.2.00.0000;

BRASIL. Corregedoria Nacional de Justiça. Provimento no 43. Brasília, 17 de abril de 2015;

BRASIL. Instituto Nacional de Colonização e Reforma Agrária - INCRA. Instrução Normativa no -76 . Brasília, 23 de agosto de 2013;

BRASIL. Instituto Nacional de Colonização e Reforma Agrária (INCRA). Aquisição de Imóveis Rurais por Estrangeiros. Brasília, julho de 2008. Disponível em: http://www.senado.leg.br/comissoes/CRA/ AP/AP20080702_SOCORRO.pdf. Acesso em: 26 fev. 2017;

BRASIL. Presidência da República. Casa Civil. Constituição da República Federativa do Brasil de 1988. Brasília, 5 de outubro de 1988;

BRASIL. Presidência da República. Casa Civil. Decreto no 74.965. Brasília, 26 de novembro de 1974;

BRASIL. Presidência da República. Casa Civil. Decreto no 85.064. Brasília, 26 de agosto de 1980;

BRASIL. Presidência da República. Casa Civil. Decreto-Lei no 4.657. Brasília, 4 de setembro de 1942;

BRASIL. Presidência da República. Casa Civil. Emenda Constitucional no 6 . Brasília, 15 de agosto de 1995;
BRASIL. Presidência da República. Casa Civil. Lei Complementar no 73. Brasília, 10 de fevereiro de 1993;

BRASIL. Presidência da República. Casa Civil. Lei no 4.504/64. Brasília, 30 de novembro de 1964;

BRASIL. Presidência da República. Casa Civil. Lei no 6.634/79. Brasília, 2 de maio de 1979;

BRASIL. Presidência da República/Casa Civil. Lei no 5.709. Brasília, 7 de outubro de 1971;

BRASIL. Senado Federal. Projeto de Lei n- 590, de 8 de setembro de 2015. Senador Waldemir Moka - PMDB/MS. Disponível em:

http://www25.senado.leg.br/web/atividade/ materias/-/materia/123053. Acesso em: 16 fev. 2017;

BRASIL. Supremo Tribunal Federal. Ação Cível Originária (ACO) 2463 MC/DF, Rel. Min. Marco Aurélio. Julgamento: 01/09/2016. Disponível em: http://www.stf.jus.br/portal/jurisprudencia/ listarJurisprudencia.asp?s 1=\%28ACO $\% 24$. SCLA.+E+2463.NUME.\%29+NAO+S.PR ES.\&base $=$ baseMonocraticas \&url=http://ti nyurl.com/qef6xd8. Acesso em: $16 \mathrm{fev}$. 2017;

BRASIL. Supremo Tribunal Federal. Glossário Jurídico. Brasília, 20 de fevereiro de 2017. Disponível em: http://www.stf.jus.br/portal/glossario/verV erbete. asp?letra=A\&id=533. Acesso em: 20 fev. 2017;

CORREIO BRAZILIENSE. Limites definidos. Brasília, 18 de julho de 2010, p. $12 . \quad$ Disponível em: http://www2.senado.leg.br/bdsf/bitstream/h andle/id/46296/complemento_1.htm?seque nce $=2$. Acesso em: 25 fev. 2017;

FARIAS, F. Celulose: projeto de lei que autoriza a venda de terras para estrangeiros anima setor. Canal Rural, Brasília, 24 de junho de 2016. Disponível em: http://www.canalrural.com.br/noticias/rural -noticias/celulose-projeto-lei-que-autoriza- 
venda-terras-para-estrangeiros-animasetor-62695. Acesso em: 26 fev. 2017;

FARIELLO, D. Temer que liberar venda de lotes de terra a estrangeiros. O Globo, Rio de Janeiro, 25 de maio de 2016. Disponível em: http://oglobo.globo.com/economia/temerquer-liberar-venda-de-lotes-de-terraestrangeiros-19372079. Acesso em: $26 \mathrm{fev}$. 2017;

GILIO, L; MORAES, M. A. F. de; MOREIRA, G. C; GUARDIA, A. F. T. S. Restrição à propriedade e arrendamento de terras por estrangeiros: evidências sobre efeitos nas decisões de investimento do setor sucroenergetico. In: Economic Analysis of Law Review. EALV, V. 6, $\mathrm{n}^{\circ}$ 2, p. 356-372, Jun-Dez, 2015;

HAGE, F. A. S.; PEIXOTO, M; VIEIRA FILHO, J. E. R. Aquisição de terras por estrangeiros no Brasil: uma avaliação jurídica e econômica. Núcleo de Pesquisas do Senado Federal, junho de 2012. Disponível em: https://www12.senado.leg.br/publicacoes/e studos-legislativos/tipos-de-estudos/textospara-discussao/td-114-aquisicao-de-terraspor-estrangeiros-no-brasil-uma-avaliacaojuridica-e-economica. Acesso em: 25 fev. 2017;

HODGSON, S; CULLINAN, C; CAMPBELL, K. Land ownership and foreigners: a comparative analysis of regulatory approaches to the acquisition an use of land by foreigners. [s.1.] FAO, 1999. Disponível em: http://www.fao.org/3/a-bb039e.pdf. Acesso em: 24 fev. 2017;

OLIVEIRA, E; FARIELLO, D. Governo quer autorizar compra de terras por estrangeiros para culturas perenes. Liberação deve incluir celulose, café e laranja; restrição deve ser mantida para grãos. O Globo. Disponível em: https://oglobo.globo.com/economia/govern o-quer-autorizar-compra-de-terras-porestrangeiros-para-culturas-perenes20940450. Acesso em: 15 mai. 2017.
PEREIRA, L. de P. Imóvel Rural para Estrangeiro. Vigência da Lei 5.709/71. Autorização para Adquirir. Limitação de Área. Empresa Brasileira de Capital Estrangeiro - $2^{\mathrm{a}}$ Edição Revista e Atualizada. Editora Afiliada. Curitiba, 2014;

SÃO PAULO. Tribunal de Justiça do Estado de São Paulo. Corregedoria Geral da Justiça. Parecer no 250/2010-E. São Paulo, 9 de setembro de 2010;

SÃO PAULO. Tribunal de Justiça do Estado de São Paulo. Corregedoria Geral da Justiça. Parecer no 461/2012-E. São Paulo, 5 de dezembro de 2012;

SÃO PAULO. Tribunal de Justiça do Estado de São Paulo. Mandado de Segurança n- 0058947-33.2012.8.26.0000, relator Desembargador: Guerrieri Rezende. São Paulo, 12 de setembro de 2012;

SAUER, S; LEITE, S. P. Expansão agrícola, preços e apropriação de terra por estrangeiros no Brasil. 50(3) Revista Economia Sociologia Rural, 503-524. 2012;

TAVARES, V. Câmara pode reabrir trabalhos de subcomissão que restringiu compra de terras por estrangeiros. Agro olhar. Brasília, 29 de julho de 2013. Disponível

em: http://www.olhardireto.com.br/agro/noticia s/exibir.asp?noticia=Camara_pode_reabrir _trabalhos_de_subcomissao_que_restringi u_compra_de_terras_por_estrangeiros\&id =8457. Acesso em: 26 fev 2017;

TRUFFI, R. O governo Temer prepara MP para a venda de terras a estrangeiros. Carta Capital, São Paulo, 16 de fevereiro de $2017 . \quad$ Disponível em: http://www.cartacapital.com.br/politica/go verno-temer-prepara-mp-para-venda-deterras-a-estrangeiros. Acesso em: $26 \mathrm{fev}$. 2017. 